\title{
Modelling Migration and Regional Labour Markets: an Application of the New Economic Geography Model RHOMOLO
}

\author{
Andries Brandsma \\ European Commission, Seville, Spain \\ d'Artis Kancs \\ European Commission, Seville, Spain \\ LICOS, University of Leuven, Leuven, Belgium \\ EERI Economics and Econometrics Research Institute, Brussels, Belgium \\ Damiaan Persyn \\ European Commission, Seville, Spain \\ VIVES and LICOS, University of Leuven, Leuven, Belgium
}

\begin{abstract}
The paper describes the dynamic spatial general equilibrium model, Regional Holistic MOdeL(RHOMOLO), developed by the European Commission, where the labour market equilibrium is determined by firms' labour demand, unemployment and interregional labour migration. We carry out simulations on the effects of transportation costs on regional labour markets. Our results confirm that wages and unemployment are by far the most important channels of labour market adjustment in the EU. In contrast, labour migration is found to play a secondary role. Also, the complexity and spatially inter-dependent relationship among market access, labour demand, and labour supply is found. It underlines the significance of dynamic spatial general equilibrium approach.
\end{abstract}

\footnotetext{
* Corresponding Author: Damiaan Persyn; European Commission, DG Joint Research Centre, IPTS, E-41092 Seville, Spain; Tel: +34 954487169, Fax: +34 954488300, E-mail: Damiaan.PERSYN@ec.europa.eu;

Co-Author: Andries Brandsma; European Commission, DG Joint Research Centre, IPTS, E-41092 Seville, Spain; Tel: +34 954488287, Fax: +34 954488300, E-mail: Andries.BRANDSMA@ec.europa.eu;

d'Artis Kancs; European Commission, DG Joint Research Centre, IPTS, E-41092 Seville, Spain; Tel: +34 954488447, Fax: +34 954488300, E-mail: d'Artis.Kancs@ec.europa.eu.
} 
JEL Classifications: C68, D58, F22, J20, J61, J64, O15

Key words: Labour Migration, Unemployment, Wage, New Economic Geography, Dynamic Spatial General Equilibrium Model

\section{Introduction}

Labour markets serve as a key channel of adjustment to macroeconomic shocks such as regional integration and economic crisis (Blanchflower and Oswald, 1995). Theory suggests that labour markets adjust in response to macroeconomic and policy shocks through several channels such as changes in unemployment, labour force participation, worker remuneration, and labour migration (Agenor 1996).

Depending on the characteristics of the regions and the preferences of people, firms, and workers may respond differently through different channels of adjustment. At economic crisis, individuals may decide that the region no longer provides them with the opportunities they desire and leave it in search for better opportunities. However, it is unlikely that all the people who decide to leave are those who directly lost their jobs as a result of the economic crisis. People who were unemployed prior to the shock may leave as well, if they see the likelihood of finding jobs is decreasing due to the economic crisis. Even people with jobs may leave, if regional wages are depressed, or if they fear that the region is in decline and they may be next in line for losing their jobs. Another possible adjustment of regional labour markets is through labour force participation which may decrease. Some of the people who lose their jobs may decide to take early retirement, pursue goals outside of the labour market, or decide that the best thing for their future prospects is to undertake further training. A further mechanism of adjustment is through changes to wages. A decrease in labour demand may have a negative impact on wages. A decrease in wages may, in turn, help to mitigate the adverse effect of the initial reduction in demand for labour by attracting new firms into the region, creating new jobs.

According to Blanchard and Katz (1992) and Decressin and Fatás (1995), regional labour markets are fundamentally different from national labour markets, and regionspecific shocks trigger different adjustment mechanisms compared to national shocks. For example, in the EU there is more inter-regional migration in response to regionspecific shocks than international migration in response to country-specific shocks 
(European Commission 2013). A second reason to consider labour markets at the regional level is the pattern and degree of specialization in the production of goods and services, which is higher at the regional level than at the national level. Thus, analyzing national labour market response to shocks would give a blurred picture. Third, regions may also differ in their response to macroeconomic shocks due to regional characteristics in labour supply. Finally, looking at inter-regional dynamics is likely to provide more policy-relevant results, as many of them may average out at the national level.

From the policy perspective, the particular channels, through which the adjustments occur, have policy implications (Boeters and Savard 2012). For example, in regional development policy, there is a debate regarding the appropriateness of people-based policies versus place-based strategies (Barca et al. 2012). Regional policy could end up benefiting new entrants to the region rather than the initial target population or community for instance. In order to capture the inter-regional dynamics and assess the relative strength of the adjustment channels, a dynamic spatial general equilibrium approach is an useful analytical tool.

This paper describes the modelling approach of regional labour markets in the newly developed dynamic spatial general equilibrium model, Regional Holistic MOdeL (RHOMOLO), where the labour market equilibrium is determined by firms' labour demand, a wage-curve with unemployment and inter-regional labour migration. The key parameters of the RHOMOLO model are estimated because these parameters are not available in the literature for labour migration across all Nomenclature of Territorial Units for Statistics (NUTS2) regions in the EU's 27 member countries.

In order to fully illustrate the potentials of the proposed dynamic spatial general equilibrium approach, we carry out simulations about the effects of transportation costs in three different regional integration scenarios. In the first scenario, transportation costs are reduced symmetrically to and from a single region to trace the dynamics of the labour market response. In the second scenario, transportation costs are reduced symmetrically between a small group of regions. This scenario sheds light on the effects of transport infrastructure projects. In the third scenario, transportation costs between all EU regions are reduced asymmetrically and simultaneously, in relation to the approved Trans-European Transport Network (TEN-T) priority projects until 2020.

Our results confirm that wages and unemployment are by far the most important adjustment channels. Improving regional accessibility by around 3\% would increase real wages by around $0.3 \%$ and reduce unemployment by around $0.3 \%$. In contrast, 
labour migration plays a secondary role in regional labour market adjustments in the EU. The multiplier effect of improved regional accessibility on net labour migration is around 0.01 , compared to 0.1 of multiplier effect of market access on real wages and unemployment. These results are new and have not been reported before. Our results also suggest that the relationship among market access, wage rate, labour demand, and supply is complex and spatially inter-dependent, which underlines the relevance of dynamic spatial general equilibrium approach.

\section{Conceptual Framework}

\section{A. Overview of the Regional Holistic MOdeL(RHOMOLO) Model}

Regional Holistic MOdeL(RHOMOLO) is a dynamic spatial general equilibrium model, which recently have been developed by the European Commission (Brandsma et al. 2013). In order to assess spatially and temporally specific impacts of public policies, the model incorporates two important features: (i) the endogenous choice of location of workers and firms among all EU regions, regional linkages through trade flows, factor mobility, and knowledge spillovers; and (ii) inter-temporal investment decisions by firms to increase their productivity, and by workers to increase their skills, i.e., human capital.

RHOMOLO is constructed in the framework of a spatial computable general equilibrium, incorporating key aspects of new economic geography models (Krugman 1991). In the model, the global economy consists of regional economies in the EU and one aggregate economy capturing the rest of the world. Each economy is disaggregated into six sectors. RHOMOLO version 2 is based on data at the Nomenclature of Territorial Units for Statistics(NUTS2) level, covering 267 regions of the EU, and follows the Statistical Classification of Economic Activities in the European Community (NACE) version 2 classification of 6 sectors of economic activity. ${ }^{1}$ The temporal coverage reaches from the base year of 2007 up to the long-run steady state growth path, which can be extended when integrating with other long-run macroeconomic

${ }^{1}$ Both dimensions can be expanded to any level of geographical and sectoral disaggregation at which sufficient socio-economic data are available. 
models, such as QUartely European Simulation Tool(QUEST).

Each region hosts two types of sectors: perfectly competitive and imperfectly competitive ones, implying that the output price, $p_{i, o, d}$ of firms is higher than marginal costs, $M C_{i, o, d}$ :

$$
p_{i, o, d}=\frac{1}{\theta-1} M C_{i, o, d}
$$

where $\frac{1}{\theta-1}$ is the elasticity of total demand, and where origin region is $o$, destination region is $d$, and sector is $i$.

Each region is endowed with two types of production factors: labour and capital. Labour supply is further disaggregated according to the education levels of the workers: low, medium, and high-skill. The regional supply of labour is determined by labour endowment in the previous period plus population growth and net migration because workers are mobile both between regions and between sectors. Sector-specific capital stocks evolve according to the last period's capital stock minus depreciation plus new investments into capital.

There are three types of economic agents in the model: households, governments, and firms. Most of the household income is spent on the consumption of goods and services, and the rest is saved. The RHOMOLO model includes the representation of two types of governments: national and regional. Governments receive income mainly from taxes. Both regional and national governments demand goods and services, transfer resoures, and save part of their income.

Each region hosts two types of sectors: perfectly competitive and imperfectly competitive ones. Firms in the perfectly competitive sector produce a homogenous good of public services under constant returns to scale. Monopolistically competitive sectors exhibit increasing returns to scale and consist of inter-regionally mobile firms, which produce horizontally differentiated goods. Following Krugman (1991), we assume Chamberlinian monopolistic competition with free entry and exit of firms. Hence, output prices are equal to marginal costs plus a mark-up, which depends on the elasticity of substitution between varieties of differentiated goods. Both types of goods being traded between all regions are subject to trade costs.

RHOMOLO is solved in a recursively dynamic framework. Because of the detailed regional and sectoral dimensions, it would be impossible to implement full intertemporally consistent computations in RHOMOLO. The recursive dynamic framework contains a series of static equilibria. Three types of factors, physical capital, human 
capital, and knowledge capital, are accumulated endogenously between periods, according to the respective laws of motion. ${ }^{2}$ As in all recursive dynamic models with myopic expectations, RHOMOLO assumes that the behaviour of inter-temporally optimising agents depends only on the current and past states of the economy, not on the inter-temporal optimisation.

\section{B. Labour Market}

The labour market in RHOMOLO links changes in regional unemployment rates with changes in regional real wages. In RHOMOLO, the wage curve describes the negative relationship between the level of unemployment and wages that arises when these variables are considered at the regional level. According to Blanchflower and Oswald (1995), the wage curve summarises the fact that "A worker who is employed in a region of high unemployment earns less than an identical individual who works in a region with low joblessness". Search, matching, bargaining, and efficiency wage models with microfoundations (Boeters and Savard 2012) result in a wage-curve type relationship.

\footnotetext{
${ }^{2}$ Conceptually, it is possible to add updating mechanisms for other variables, such as public expenditure, transfers, technological change, or debt accumulation.
} 


\section{Figure 1. Wage Curve}

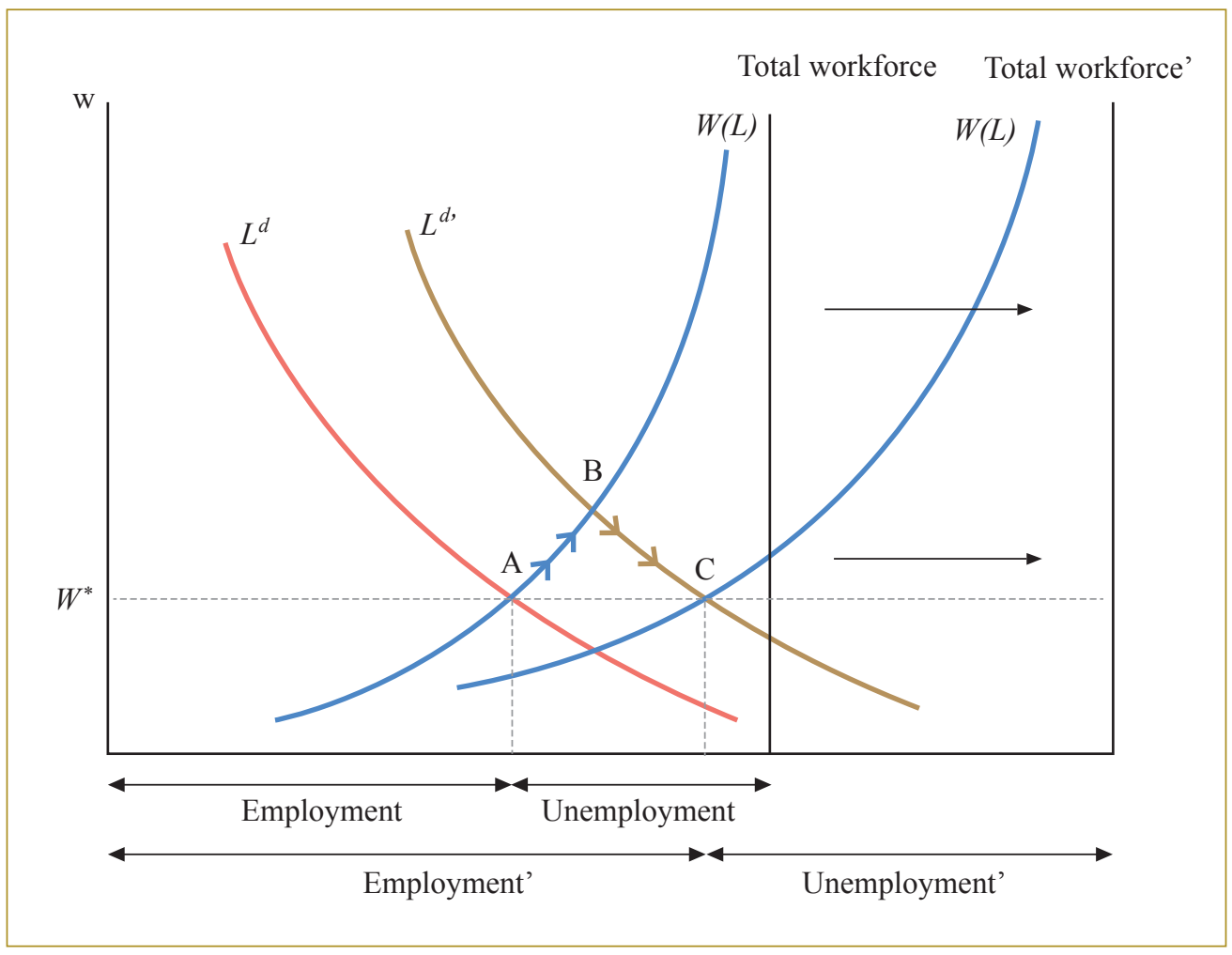

Figure 1 is an illustration of the partial equilibrium effect of a single shift in labour demand $(\mathrm{A} \rightarrow \mathrm{B})$, and subsequent in-migration $(\mathrm{B} \rightarrow \mathrm{C})$, on regional wages, employment, and unemployment. The shift has a temporary effect on wages and the unemployment rate, and a permanent effect on the size of the local labour force.

Figure 1 illustrates the effect of an increase in regional labour demand using a stylised neo-classical labour market model for a small regional economy. An increase in regional labour demand will, in the short run, lead to higher regional wages and a decrease in the unemployment rate $(\mathrm{A} \rightarrow \mathrm{B})$. Over time, migration causes both wages and unemployment rates to return to their pre-shock level $(B \rightarrow C)$. In general, equilibrium models such as RHOMOLO with many simultaneous channels of adjustment, everything else is not fixed. Firms will be exiting or entering the region which additionally shifts labour demand, there will be effects in other regions via tradelinkages, factor movements, and knowledge spillovers with feedback to the region under consideration. While Figure 1 is illustrative of the static effects which can be expected 
from a single regional shock in a simple labour market model, a dynamic spatial general equilibrium framework is necessary for assessing the spatial and temporal dynamics of public policies.

The version of RHOMOLO used in this paper abstracts from individuals' labour market participation decisions. In reality, participation decisions play an important role as a channel of labour market adjustment to macroeconomic shocks. This is especially the case of the EU (Decressin and Fatás 1995, Obstfeld and Peri 2000, Bentivogli and Pagano 2003). Therefore, future versions of RHOMOLO will model labour market participation decisions starting from individuals' optimal labour-leisure choice, as described in Brandsma et al. (2013) and Persyn and Kancs (2014).

\section{Empirical Implementation}

The empirical implementation of the RHOMOLO model requires data on the level of exogenous and endogenous variables for the base year of 2007, and numerical values for all the model's parameters. The base year data are compiled in the form of an inter-regional Social Accounting Matrix (SAM) (Potters et al. 2013, Ivanova et al. 2010). Some of the structural parameters of the labour market module are drawn from the literature. In particular, following the empirical literature on the wage curve, we choose a wage-unemployment elasticity of -0.1 (Blanchflower and Oswald 1995). ${ }^{3}$ The remaining labour market parameters, which are not available in the literature, are estimated econometrically.

\section{Estimation of Migration Elasticities}

\section{A. Specification of an Estimable Migration Equation}

In order to derive an estimable migration equation relating the aggregate interregional migration flows to behavioural parameters in the theoretical model, we follow

\footnotetext{
${ }^{3}$ Future versions of RHOMOLO will make it possible to estimate skill- and country-specific elasticities, based on evidence such as presented, for example, in Sanz-de Galdeano and Turunen (2006).
} 
Sorensen et al. (2007) and Grogger and Hanson (2011), and start from the individual migration decision. Consider a worker $k$ from origin region $o$, maximising indirect utility, $V_{k o r}$, across all possible destinations $r$. Destination $d$ will be chosen if

$$
\begin{gathered}
V_{k o d}>V_{k o r}, \forall r \in \text { all regions, } R \\
V_{k o d}=Z_{o d} \beta+\xi_{o d}+e_{k o d}
\end{gathered}
$$

where the indirect utility $V_{k o r}$ of worker $k$ migrating from origin region $o$ to destination region $d$, is determined by the characteristics $Z_{\text {od }}$. Region $d$ may vary with respect to origin region $o$, such as bilateral distance. The term $Z_{o d} \beta$ represents the utility the worker receives from these characteristics, where $\beta$ is a vector of marginal utilities. The error term $\xi_{o d}$, represents unobserved location characteristics. $Z_{o d} \beta$ and $\xi_{\text {od }}$ assign the same utility level to all workers considering migration from $o$ and to $d$. The idiosyncratic error term $e_{\text {kod }}$, which varies across both workers and regions, accounts for the fact that not all workers from the same region choose the same destination. The probability that location $d$ is chosen by a resident of region $o$ then equals

$$
\begin{gathered}
\operatorname{Pr}\left(V_{k o d}>V_{k o r}\right) \quad \forall d \neq r \\
\operatorname{Pr}\left(\left[e_{k o d}-e_{k o r}\right]>\left[Z_{o r} \beta-Z_{o d} \beta\right]+\left[\xi_{o r}-\xi_{o d}\right]\right) \quad \forall d \neq r
\end{gathered}
$$

Now assume that the idiosyncratic error term $e_{\text {kod }}$ follows an iid extreme value distribution. McFadden (1973) shows this yields the following probability for a worker $k$ to migrate from o to $d$ :

$$
\operatorname{Pr}\left(M_{k o d}=1\right)=\frac{\exp \left(Z_{o d} \beta+\xi_{o d}\right)}{\sum_{d=1}^{R} \exp \left(Z_{o d} \beta+\xi_{o d}\right)}
$$

Berry (1994) in turn shows that probability (1) of migrating from $o$ to $d$ can be interpreted as the share of workers from $o$ migrating to $d$. Following Sorensen et al. (2007), we therefore write the share of migrants from $o$ to $d$ as: 


$$
S_{o d}=\operatorname{Pr}\left(M_{k o d}=1\right)=\frac{\exp \left(Z_{o d} \beta+\xi_{o d}\right)}{\sum_{d=1}^{R} \exp \left(Z_{o d} \beta+\xi_{o d}\right)}
$$

and the share of those who stay in region $o$ as:

$$
s_{o o}=\operatorname{Pr}\left(M_{k o o}=1\right)=\frac{\exp \left(Z_{o o} \beta+\xi_{o o}\right)}{\sum_{d=1}^{R} \exp \left(Z_{o d} \beta+\xi_{o d}\right)} .
$$

Dividing Equation (2) by (3) and applying a logarithmic transformation yields a simple estimable migration equation:

$$
\ln \left(\frac{s_{o d}}{s_{o o}}\right)=\ln \left(\frac{\exp \left(Z_{o d} \beta+\xi_{o d}\right)}{\exp \left(Z_{o o} \beta+\xi_{o o}\right)}\right)=\left[Z_{o d} \beta-Z_{o o} \beta\right]+\left[\xi_{o d}-\xi_{o o}\right]
$$

Relaxing the iid assumption. The iid assumption on the idiosyncratic part of the error-term implies that there exists no correlation between individuals' tastes for locations. This is highly unlikely in our application on interregional migration within the EU, where cultural and language differences imply that individuals who have a taste for a certain region within a country are likely to have a taste for other regions within the same country (Persyn and Torfs 2012). We therefore allow $e_{k o d}$ to be correlated within countries, while maintaining the iid assumption between countries. ${ }^{4}$

One denotes Country index by $c$, country of destination by $c_{d}$, giving indirect utility as,

$$
V_{k o d}=Z_{o d} \beta+\xi_{o d}+\sigma \zeta_{o c_{d}}+(1-\sigma) e_{k o d}
$$

with $\sigma$ a measure of within-country correlation in taste.

The probability that an individual $k$ will choose to migrate from region $o$ to region

\footnotetext{
${ }^{4}$ Using countries as nests ignores the fact that some countries have important internal boundaries which would require constructing nests within countries; or the fact that tastes might be correlated between different countries, for example between countries that share a common language or joint history. We leave these issues to future work.
} 
$d$ is then given by the product of the conditional probability that the individual will choose any region in the country $c_{d}$, times the probability that the individual will choose the particular region $d$ within the country.

Following Sorensen et al. (2007), this probability can in turn be used to derive an estimable migration equation, which relates the observable aggregate migration shares to the underlying model's structural parameters

$$
\ln \left(\frac{s_{o d}}{s_{o o}}\right)=\left(Z_{o d}-Z_{o o}\right) \beta+\sigma \ln \left(s_{o d \mid c_{d}}\right)+\left(\xi_{o d}-\xi_{o o}\right)
$$

\section{B. Data Construction}

Dependent variable: inter-regional labour migration. The estimation of migration Equation (5) requires a complete matrix of gross bilateral migration flows between all Nomenclature of Territorial Units for Statistics(NUTS2) regions in the EU. However, such data are currently not available. In order to address this issue, we merge two available datasets: Eurostat's data on within-country interregional migration flows and OECD's data on international migration. This will allow us to construct an imputed data matrix of bilateral migration flows, which will be subsequently used in the empirical estimations.

Data on migration between NUTS2 regions within countries is available from Eurostat for most of the EU member states. ${ }^{5}$ The first step in constructing an approximate dataset of gross bilateral migration flows between NUTS2 regions consists of calculating migration probabilities between every pair of regions within each country. Secondly, international migration flows without any regional dimension were obtained from the OECD. These international migration flows were subsequently 'regionalised', assuming that international migrants distribute themselves between the regions of the destination country according to the same pattern as within-country migrants do. Similarly, the international migrants are assumed to originate from specific regions of origin in the source country in the same proportions as the within-country migrants originate from different regions in the source country.

\footnotetext{
${ }^{5}$ The countries for which internal regional migration data are available are Austria, Belgium, Bulgaria, the Czech Republic, Spain, Finland, Hungary, Italy, the Netherlands, Poland, Romania, Sweden, Slovenia, and Slovakia.
} 
More formally, use $f_{\text {od }}$ to denote the migration flow of workers between origin region $o$ in country $c_{o}$ and region $d$ in destination country $c_{d}$, which is to be imputed. Use $F_{c_{o} c_{d}}$ to denote the aggregate international migration flow between countries $C_{o}$ and $C_{d}$. Write $m_{o\left(c_{0}\right)}$ for the share of within-country migrants originating from region $o$, and similarly $m_{o\left(c_{d}\right) d}$ for the share of people who migrate to region $d$, originating within country $c_{d}$. We then assume that the migration flow between regions $o$ and $d$ can be approximated by

$$
f_{o d}=F_{c_{o} c_{d}} \cdot m_{o\left(c_{o}\right)} \cdot m_{\left(c_{d}\right) d}
$$

It is an approximation, and will introduce errors if the true distribution of international migrants differs significantly from the observed distribution of withincountry migrants. One can imagine, for example, that Austrian migrants would have a stronger tendency to migrate towards northern Italy when compared to the average Italian inter-regional migrant, given the geographic proximity of Austria to northern Italy. Whereas we believe that this effect exists and will affect the estimated migration flows, its actual impact on the estimated parameters of the migration equation is likely to be limited.

Explanatory variables: In line with the underlying conceptual framework, we measure the indirect utility of living in region $d$ for an individual from region $o$,

$$
V_{k o d}=Z_{o d} \beta+\xi_{o d}+\sigma \zeta_{o c}+e_{k o d}
$$

by the expected real income in destination region $d$ and the net of migration costs for migrating between $o$ and $d$. We approximate the real expected income in region $r$ by

$$
\text { income }_{r}=W(r) \cdot(1-u(r)) / P(r)
$$

where $W(r)$ the average local wage, $u(r)$ the unemployment rate, and $P(r)$ the local consumer price index. The migration costs are approximated by a log-linear function of the great circle distance between the geographic centre of the origin and destination NUTS2 regions. A dummy variable I (international ${ }_{\text {od }}$ ) for international migration equals 1 in the case in which region $o$ and $d$ are located in different countries. The empirical specification of the estimation equation then becomes 


$$
\begin{aligned}
\ln \left(\frac{s_{o d}}{s_{o o}}\right)=\beta_{1} \ln \left(\text { income }_{o}\right)+\beta_{2} \ln \left(\text { income }_{d}\right)+\beta_{3} \ln \left(\text { distance }_{o d}\right) \\
+\beta_{4} I\left(\text { international }_{o d}\right)+\beta_{5} \ln \left(s_{o d \mid c_{d}}\right)+\left(\xi_{o d}-\xi_{o o}\right)
\end{aligned}
$$

The data on wages, the unemployment rate, and Consumer Price Index (CPI) were taken from the Eurostat regional databases. The year 2004 was chosen to perform the analysis, as this year has the best data coverage. ${ }^{6}$ Although, according to the underlying conceptual framework, coefficients $\beta_{1}$ and $\beta_{2}$ should be of opposite sign and of equal size, we follow Kancs (2011) and do not impose this restriction in our empirical application. We report the empirical results for specifications including a log-linear distance term to estimate the elasticity of migration with respect to distance. In the simulations using RHOMOLO, which will be discussed in Section IV, a fifth-order polynomial in distance will be used to obtain results which are as realistic as possible.

\section{Empirical Results}

Using the imputed interregional migration flows obtained from Equation (6), Equations (4) and (5) were subsequently estimated. The estimation of Equation (5) requires an instrumental variable approach due to the endogeneity of the conditional probability. Following the common approach in the literature on discrete choice in the context of product demand estimation, we chose the number of regions in a country as an instrument for the probability of choosing a specific region as the destination of choice, conditional on the choice of destination country. The share of people choosing a particular region in a country will be inversely related to the number of regions in the country. The number of regions in a country is exogenous to the migration decision in itself, as the size of countries and the number of NUTS2 regions contained in them are clearly unrelated to contemporary migration patterns.

${ }^{6}$ Choosing a different year does not materially affect the results. 


\section{Table 1. Estimation Results}

\begin{tabular}{|c|c|c|}
\hline \multicolumn{3}{|c|}{ Dependent variable: $\ln \left(\frac{S_{o d}}{S}\right)$, is the share of inter-regional migration } \\
\hline & I & II \\
\hline $\ln \left(\right.$ income $\left._{o}\right)$ & $\begin{array}{c}-0.506^{* * *} \\
(0.0197)\end{array}$ & $\begin{array}{c}-0.514^{* * *} \\
(0.0243)\end{array}$ \\
\hline $\ln \left(\right.$ income $\left._{d}\right)$ & $\begin{array}{c}0.820 * * * \\
(0.0236)\end{array}$ & $\begin{array}{c}0.773 * * * \\
(0.0275)\end{array}$ \\
\hline $\ln \left(\right.$ distance $\left._{o d}\right)$ & $\begin{array}{c}-0.455^{* * *} \\
(0.0202)\end{array}$ & $\begin{array}{c}-0.650 * * * \\
(0.0330)\end{array}$ \\
\hline $\mathrm{I}\left(\right.$ international $\left._{o d}\right)$ & $\begin{array}{c}-4.482^{* * *} \\
(0.048)\end{array}$ & $\begin{array}{c}-4.06^{* * *} \\
(0.067)\end{array}$ \\
\hline $\ln \left(\right.$ conditional share $\left._{d}\right)$ & & $\begin{array}{c}-1.221^{* * *} \\
(0.0423)\end{array}$ \\
\hline constant & $\begin{array}{c}-4.163^{* * * *} \\
(0.292)\end{array}$ & $\begin{array}{c}-5.563 * * * \\
(0.426)\end{array}$ \\
\hline Number of observations & 14,485 & 14,485 \\
\hline
\end{tabular}

(Note) OLS Estimates of Equation (7). I (international od $_{\text {) }}=$ Dummy variable for international migration Standard errors in parentheses ${ }^{*} p<0.10^{* *} p<0.05^{* * *} p<0.01$

Column I of Table 1 shows the results of estimating Equation (7) using the OLS estimator. Column II reports the estimation of instrumental variables described above. The estimated effect of income in the destination region decreases and the elasticity of distance increases when taking into account the endogeneity of the conditional probability, but overall the results of OLS and IV are rather similar. The size of the effect of the international migration dummy I(international $\left.{ }_{o d}\right)$ is remarkable, emphasising the importance of international borders that often correspond to important cultural and language barriers on labour mobility. The coefficient on the conditional share has the opposite sign and is outside of the theoretically consistent range between 0 and 1 . In this light, we opted to use the OLS estimates in the simulation analysis. It is not harmful because the difference between the OLS and IV estimates is quite small.

Being rooted in the discrete choice theory, the estimated migration model allows us to infer the structural parameters governing individual behaviour from observable 
aggregate migration flows. An important advantage of this approach is that when assessing the effects of policy simulations, the predicted migration flows will obey key macro-accounting rules. In particular, the predicted increase in migration inflow resulting from an increasing attractiveness of regions must imply an equal increase in outgoing migration from other regions, such that the total EU population is unaffected by internal migration within the EU. Such properties do not hold when modelling migration flows in an ad hoc way (Schmidheiny and Brülhart 2011).

\section{Policy Simulations: three Scenarios of Economic Integration}

\section{A. Simulation Setup}

In this section, we use the example of trade cost reduction to simulate the impact of economic integration on regional labour markets. We carry out simulations showing the effects of transportation costs in three different economic integration scenarios, and assess its impact on regional labour markets. In the first scenario, transportation costs are reduced symmetrically to and from a single region. This scenario allows us to trace the dynamics of the labour market response to an isolated shock. In the second scenario, transportation costs are reduced symmetrically between a small group of regions. This scenario sheds light on the effects which may be expected from transport infrastructure projects, enhancing accessibility among several regions. In the third scenario, transportation costs between all EU regions are reduced asymmetrically and simultaneously, based on the approved TEN-T(Trans-European Transport Network) priority projects until 2020.

Traditionally, labour migration has been studied in reduced form models, where the key explanatory variables, such as wages and unemployment, are determined a priori and fixed exogenously. However, according to the underlying theoretical and empirical framework, workers' decisions about migration and location depend on inter-regional differences in indirect utility, which in turn depend on the wage rate, the unemployment rate, consumer price index, and distances between all regions. Given that the wage rate of workers and regional price index depend on the size of a region's labour force, all these variables are endogenous, which explains our choice of the dynamic spatial general equilibrium framework - RHOMOLO. 
Migration: In RHOMOLO, the simulated population change in region $r$ with labour force $L_{r}$ due to migration is the difference between incoming and outgoing migration, or

$$
\sum_{o} L_{o} \cdot S_{o r}-\sum_{d} L_{r} \cdot S_{r d}
$$

where the migrating population shares, $s_{\text {od }}$, are given by Equations (2) and (3), using the corresponding estimates from Table 1 for the coefficient vector, $\beta$. The effect of a change on a covariate in vector, $Z_{\text {od }}$, is calculated by comparing the model-predicted migration flows using the observed covariates, with the model-predicted flows when using counterfactual dataset in which the original covariates have been replaced.

Employment: As participation decisions are not considered in the current version of RHOMOLO, the workers taking up the newly created jobs are either formerly unemployed, or new migrants into the region (Pissarides and Wadsworth 1989). Writing for the growth rate of a variable, the underlying labour market accounting rule implies that

$$
\begin{array}{r}
\text { employment }=\left(\frac{\text { employment }}{\text { labour force }}\right) \cdot(\text { labour force }) \\
\ln (\text { employment })=\ln \left(\frac{\text { employment }}{\text { labour force }}\right)+\ln (\text { labour force })
\end{array}
$$

such that the growth of employment must equal the sum of the growth of the employment rate and the growth of the labour force which only occurs by migration.

\section{B. Symmetric Single Region Integration Scenario}

In the symmetric single region integration scenario, all bilateral transportation costs between the single region, BE24, and all other EU regions were reduced proportionally by 10 percent. For illustration purposes, we select a region in Belgium, because this region is affected by a TEN-T priority project, TEN-T 2: High-speed railway axis ParisBruxelles/Brussel-Köln-Amsterdam-London. Limiting the integration scenario to one region in this simulation exercise allows us to better isolate its effects on regional labour 
markets, and may serve as a reference.

The results of a symmetric decrease of transport costs to and from a single region on both the region itself and its neighbouring regions are reported in Figures 2 6. Figure 2 shows the growth rates of the different variables in the years following the shock and focuses on the dynamic labour market response over time. The effect of the symmetric 10 percent decrease in transportation costs to and from the Belgian region BE24 (Vlaams Brabant) on the region itself, and a neighbouring region BE22 (Limburg) which is the region to the east of BE24 region. The effects on other nearby regions are comparable. The labour market impact is somewhat similar to the stylised positive shock to the labour market which was illustrated in Figure 1. The total employment increases by about 0.06 percent in the first year and continues to increase at a moderate pace in the years following the shock. The workers taking up the newly created jobs are either formerly unemployed, or new migrants into the region. Indeed, in Figure 2 we see that in the first year the increase in employment of 0.06 percent is accompanied by an equal increase in the employment rate. ${ }^{7}$ The simultaneous increase in the local regional wage triggers in-migration in the years following the initial shock, with the contribution of migration increasing, and wages and the employment rate slowly subsiding. These results are in line with other studies employing the general equilibrium framework for studying labour migration at the regional level (Kancs 2011).

${ }^{7}$ The employment rate $\mathrm{E} /(\mathrm{E}+\mathrm{U})$ is equal to 1 minus the unemployment rate $\mathrm{E} /(\mathrm{E}+\mathrm{U})$. 
Figure 2. Impulse - Response Function of a Symmetric Region Integration Shock
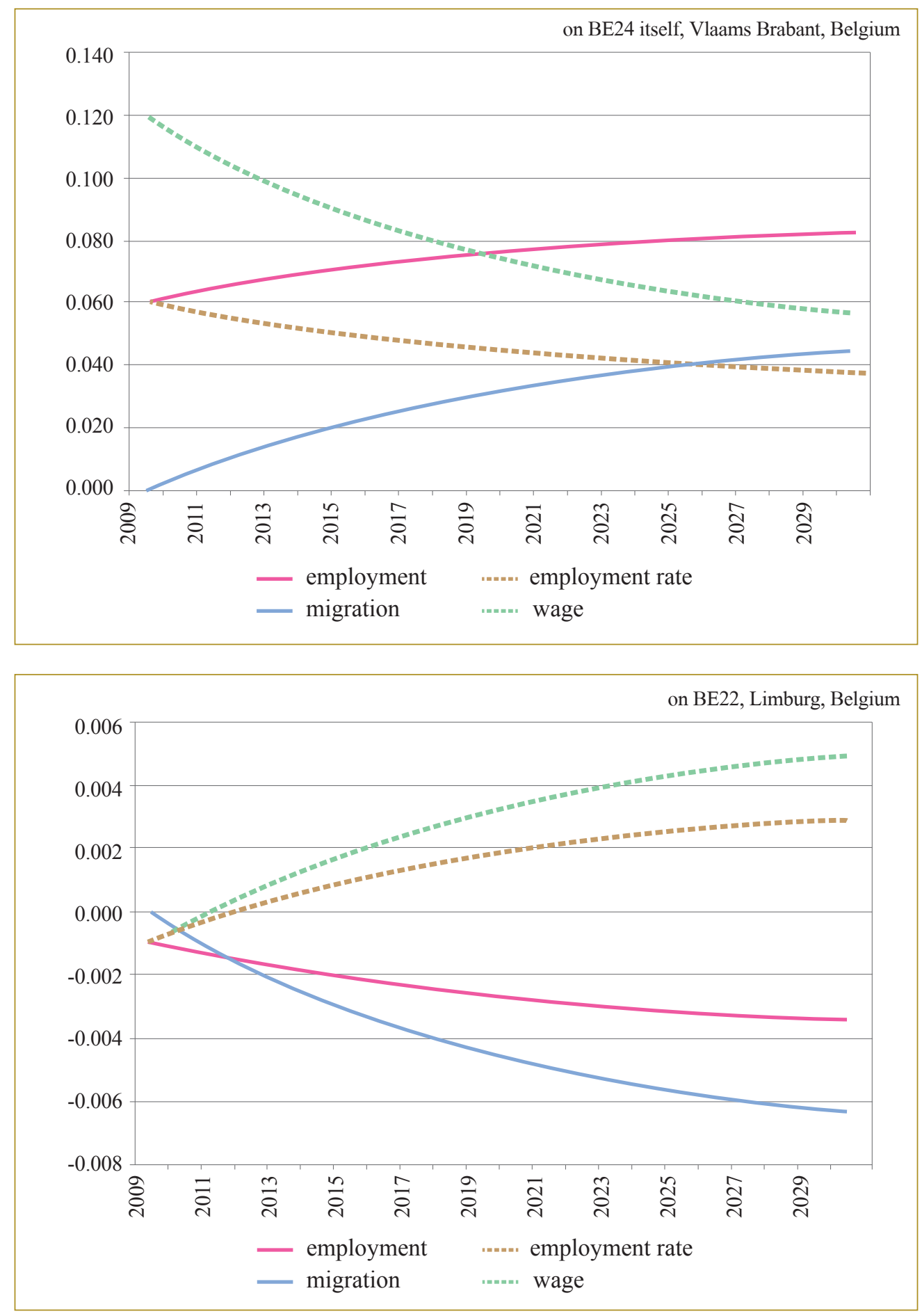
Neighbouring regions experience a decrease in transportation costs towards the integrating region, BE24, but simultaneously face an increase in the relative transportation costs towards all other regions. Whether the total employment in other regions will increase or decrease depends on their geographic location and market size, but also, on regional specialisation patterns. The labour market dynamics for the neighbouring region BE22, which are illustrated in the bottom figure of Figure 2, therefore cannot be generalised but rather serve as an example. Nevertheless, it is natural to see that the effects are about an order of magnitude smaller, when compared to the integrating region, BE24, which experiences symmetric decline in transportation costs. Different from the integrating region, there is an initial and widening negative effect on the total regional employment in the neighbouring region, with simultaneous out-migration. This is not surprising, given the incentives for migration, and the predicted increase in real wages and the employment rate in the region facing the decline in transportation cost. Also, different from the integrating region, the initial effect on real wages and the employment rate in the neighbouring region is negative, although the effects on these variables become positive around two to three years after the initial shock.

\section{Figure 3. Impact on Real Wages}

of a Symmetric Single Region Integration Shock, Belgium
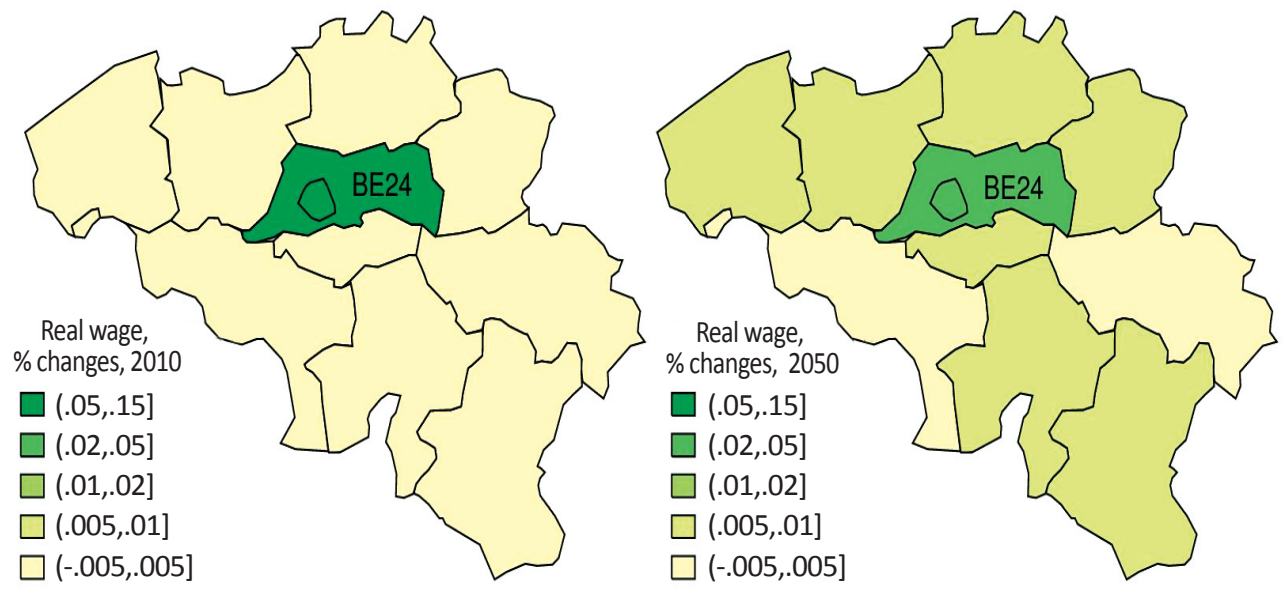

Figure 3 shows short-run (2010) and long-run (2050) impacts of 10\% improvement in the region's accessibility on real wages. Simulations are performed using the RHOMOLO v.2 model with all NUTS2 regions in EU-27, but only the Belgian regions are reported where the impact on other EU regions is of a lower order of magnitude. 
Figure 4. Impact on Unemployment of a Symmetric Single Region Integration Shock, Belgium

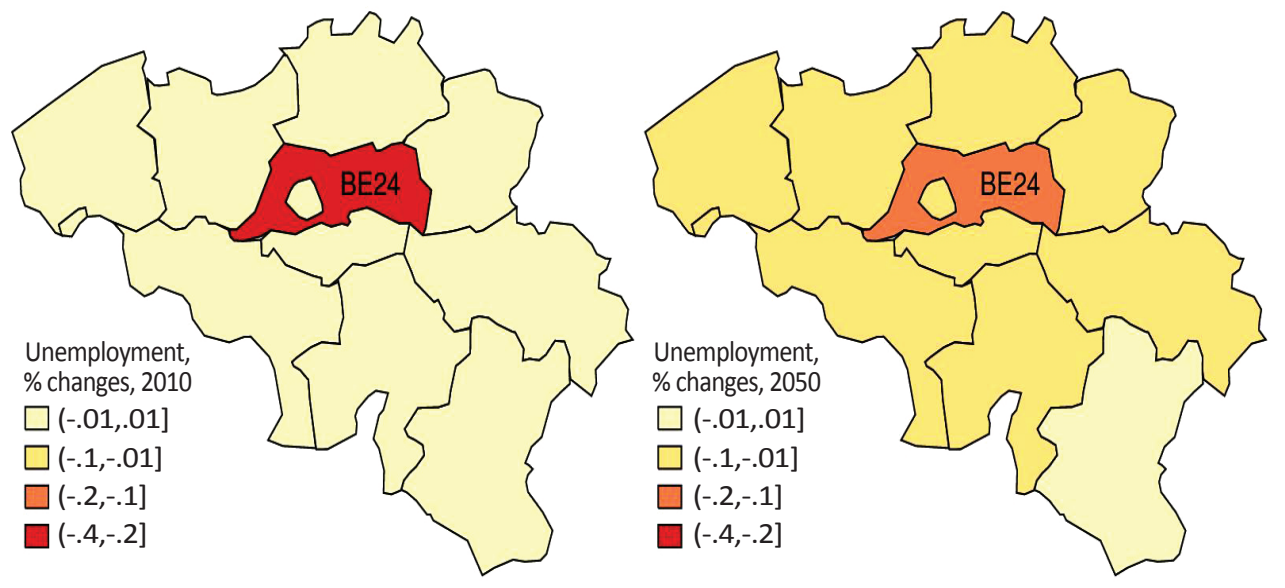

Figure 4 shows short-run (2010) and long-run (2050) impacts of 10\% improvement in the region's accessibility on unemployment.

Figure 5. Impact on Expected Income

of a Symmetric Single Region Integration Shock, Belgium

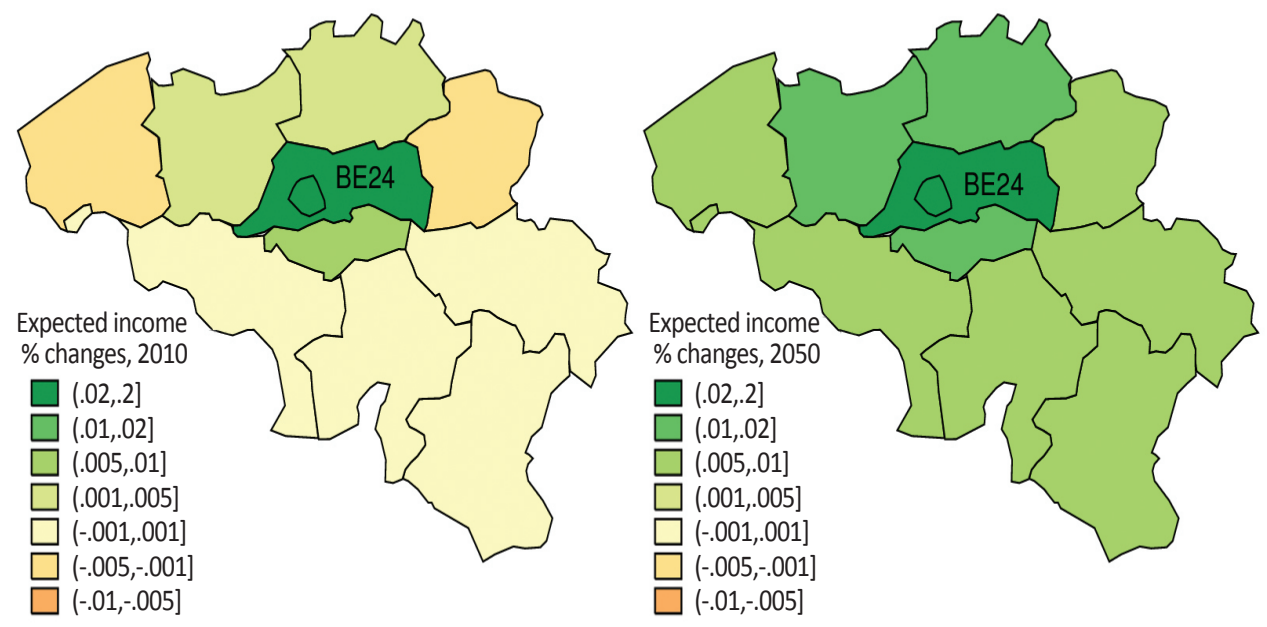

Figure 5 shows short-run (2010) and long-run (2050) impacts of 10\% improvement in the region's accessibility on expected income. 


\section{Figure 6. Impact on Labour Force of}

a Symmetric Single Region Integration Shock, Belgium
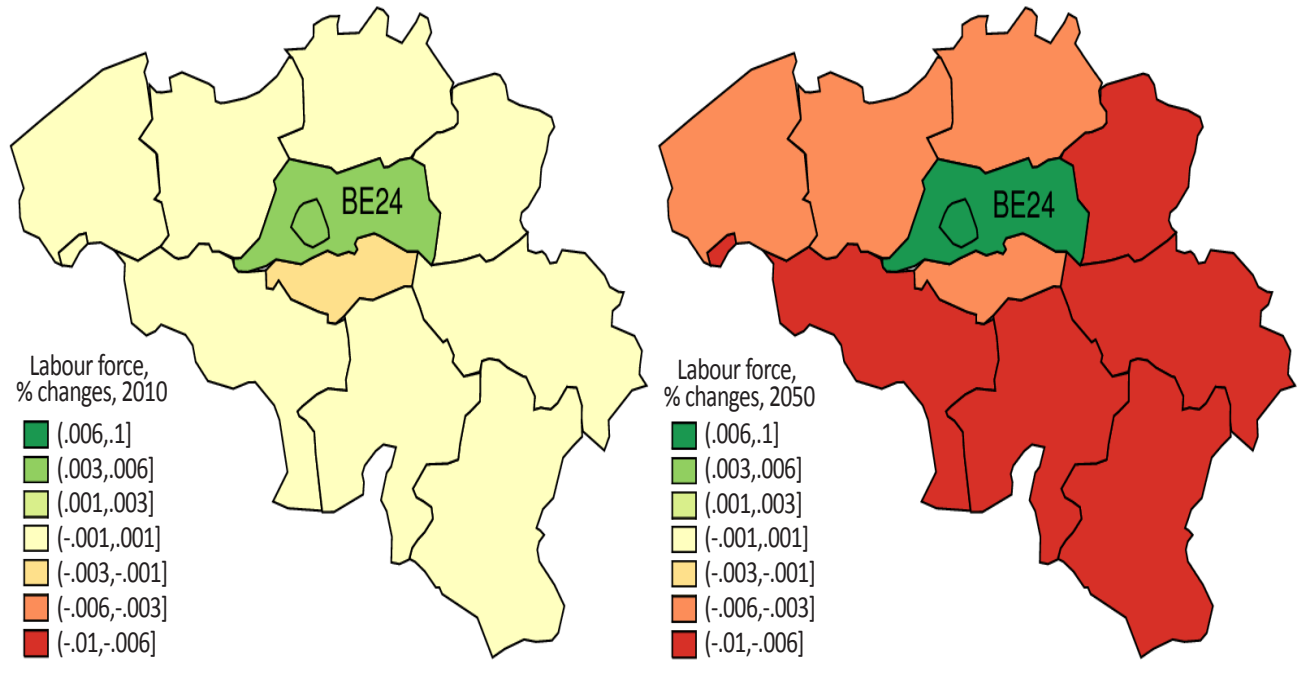

Figure 6 shows short-run (2010) and long-run (2050) impacts of 10\% improvement in the region's accessibility on labour force.

To further illustrate the temporal and spatial patterns of the regional labour market response to a shock in market integration, Figures 3 to 6 show the effects in the shortrun (2010) and long-run (2050), for all regions in Belgium.

These figures highlight that, in the short-run, the labour market effects are largely concentrated in the integrating region (BE24). In the long-run, however, the effects also spillover to the neighbouring regions. The effects on wages and unemployment rate become weaker over time in the region under consideration, while simultaneously spreading spatially and increasing in magnitude in the neighbouring regions. The effects on income and the size of the labour force in the local labour market, in contrast, grow stronger over time, while simultaneously spreading spatially. In the short-run, the labour market effect in several neighbouring regions is negative. According to Figure 5 , expected real income would decrease slightly in the northwest (West-Vlaanderen) and northeast (Limburg) in the short-run. In the long-run, however, the labour market effect is positive for all regions in the country, with increasing real wages and income, and reducing unemployment rates. The effect on labour mobility (Figure 6) is limited and the effect increases over time. Especially regions with a relatively lower income (in the south and east of Belgium) experience larger outflows. Note, however, that this 
simulation does not take into account the fact that intra-country mobility might be lower in Belgium due to interregional language differences.

\section{Symmetric Multi-Region Integration Scenario}

In this scenario, transportation costs are reduced symmetrically and exclusively between five Polish regions (PL11, PL12, PL22, PL61, and PL63). For illustration purposes, we select these five regions in Poland, because these regions are affected by two TEN-T priority projects, TEN-T 23: Railway axis Gdansk-Warszawa-BrnoBratislava-Wien, and TEN-T 25: Motorway axis Gdansk-Brno-Bratislava-Wien. This simulation is thought to reflect the effect of a single transport infrastructure project improving the connectivity between these regions. The results of this symmetric multiregion integration shock on regional labour markets in Poland are reported in Figures $7 \sim 10$, which show the long-run (2050) impacts on real wages, unemployment, expected income, and labour force, respectively. The impacts in this scenario are more complex than in the previous section because, due to shifts in the relative attractiveness of regions, inequalities may also arise between the integrating regions. 


\section{Figure 7. Impact on Real Wages}

of a Symmetric Multi-Region Integration Shock, Poland
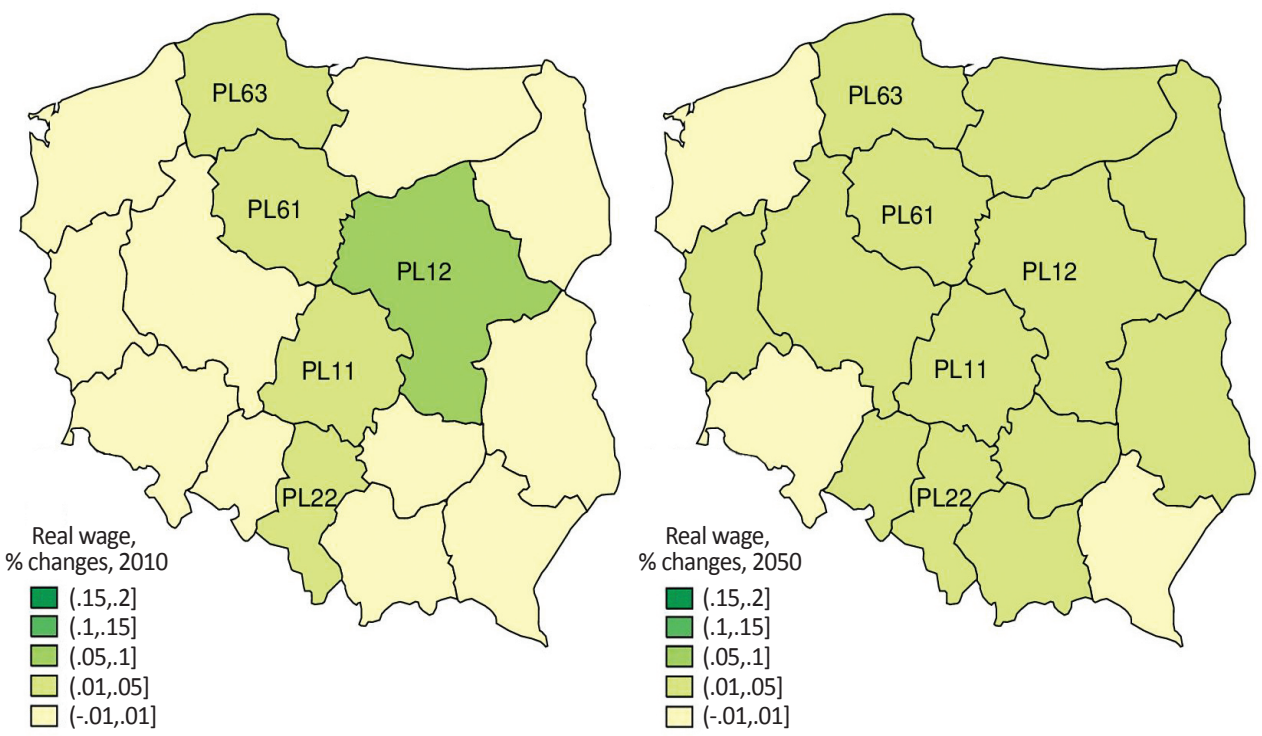

Figure 7 shows short-run (2010) and long-run (2050) impacts of improvement in the regions' accessibility on real wages. According to Figure 7, improving the accessibility of several regions would have a positive impact on real wages in all regions, though at a differentiated rate. In the short-run (left figure), workers in the capital city region, PL12, would benefit the most in terms of real wages $(+0.2 \%)$. Two effects may help to explain these results: the market access effect and the market size effect. Given that the capital city region, PL12 is located in the centre of the five integrating regions, it has the best market access vis-à-vis the other four integrating regions. Second, region PL12, has the largest internal market among the five regions, implying that the 'home-market effect' might be the strongest there. In the long-run (right figure), however, the relatively larger impact on wages in the capital city region, PL12, decreases vis-à-vis the other four integrating regions. 
Figure 8. Impact on Unemployment

of a Symmetric Multi-Region Integration Shock, Poland
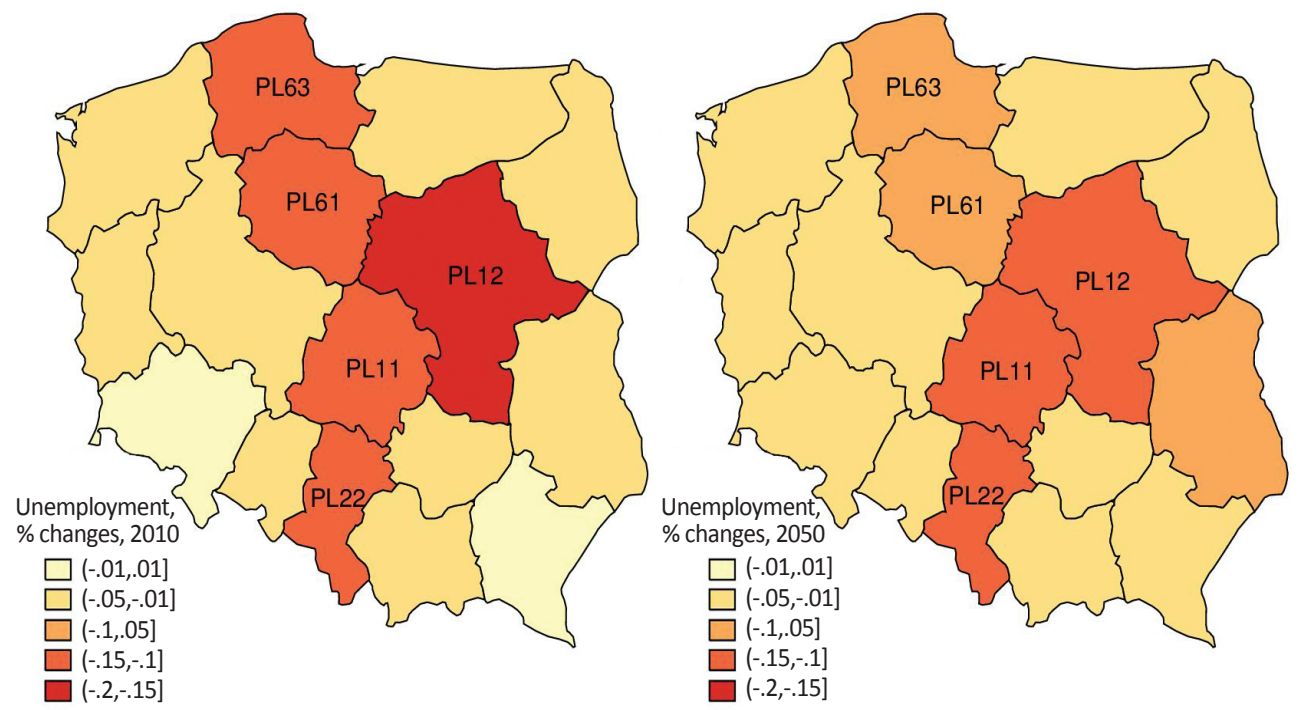

Figure 8 shows short-run (2010) and long-run (2050) impacts of improvement in the regions' accessibility on unemployment.

The impact on regional unemployment rate is negative for all regions. Similar to the impact on wages, in the short-run (left figure), workers in the capital city region, PL12, would benefit the most also in terms of unemployment $(-0.2 \%)$. The inter-regional differences in the impact of unemployment appear somewhat more persistent over time (right figure). These results are in line with empirical evidence for EU regions, which confirms significant and persistent differences in unemployment levels across the EU regions (Elhorst 2003). 

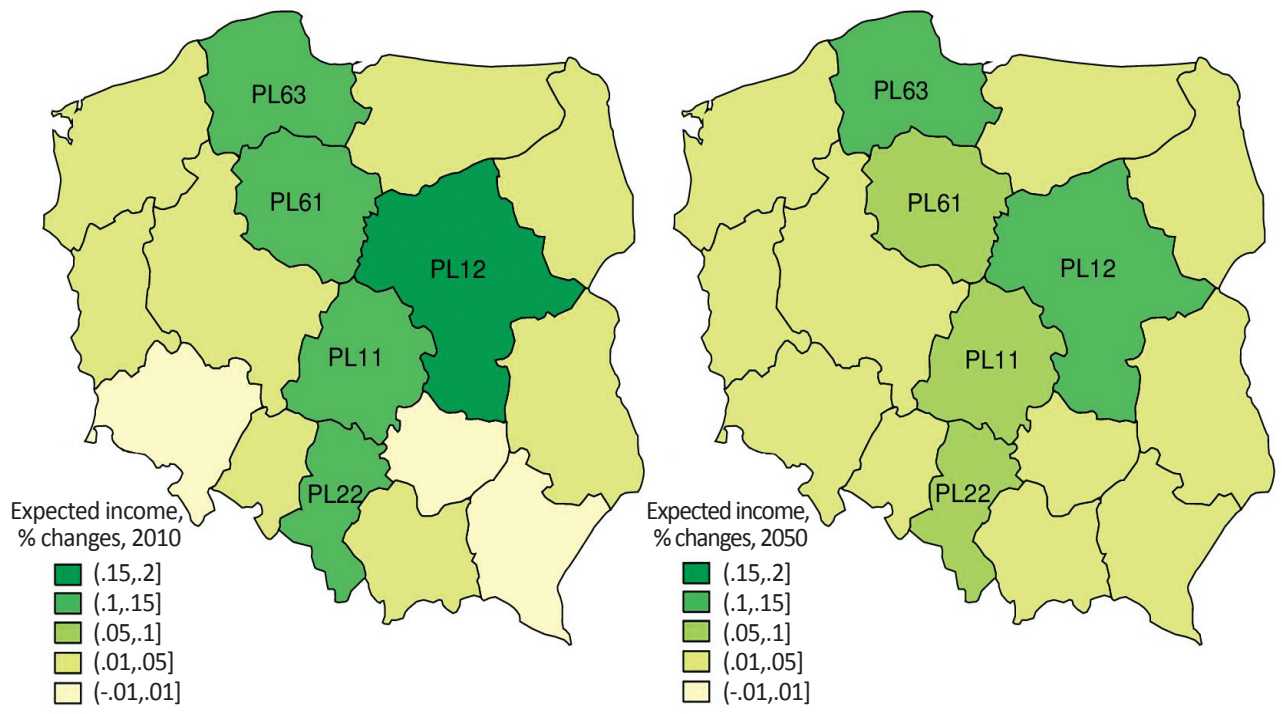

Figure 9 shows short-run (2010) and long-run (2050) impacts of improvement in the regions' accessibility on expected income.

An improvement in market access favours the integrating regions vis-à-vis other regions, particularly the capital city region, PL12, which is located in the centre of the five integrating regions, and has the largest internal market among the five regions. These findings seem to confirm those of Puga (2002), who warns that improving transport infrastructure that connect the core regions to more peripheral regions is likely to benefit the core region more in relative terms. The positive impact on the integrating regions is more pronounced in the short-run than in the long-run. Due to inter-regional linkages in goods and factor markets, the non-integrating regions also benefit from the TEN-T investments. These findings underline the importance of an inter-regional general equilibrium approach to policy questions which have spatial impacts. 
Figure 10. Impact on Labour Force

of a Symmetric Multi-Region Integration Shock, Poland
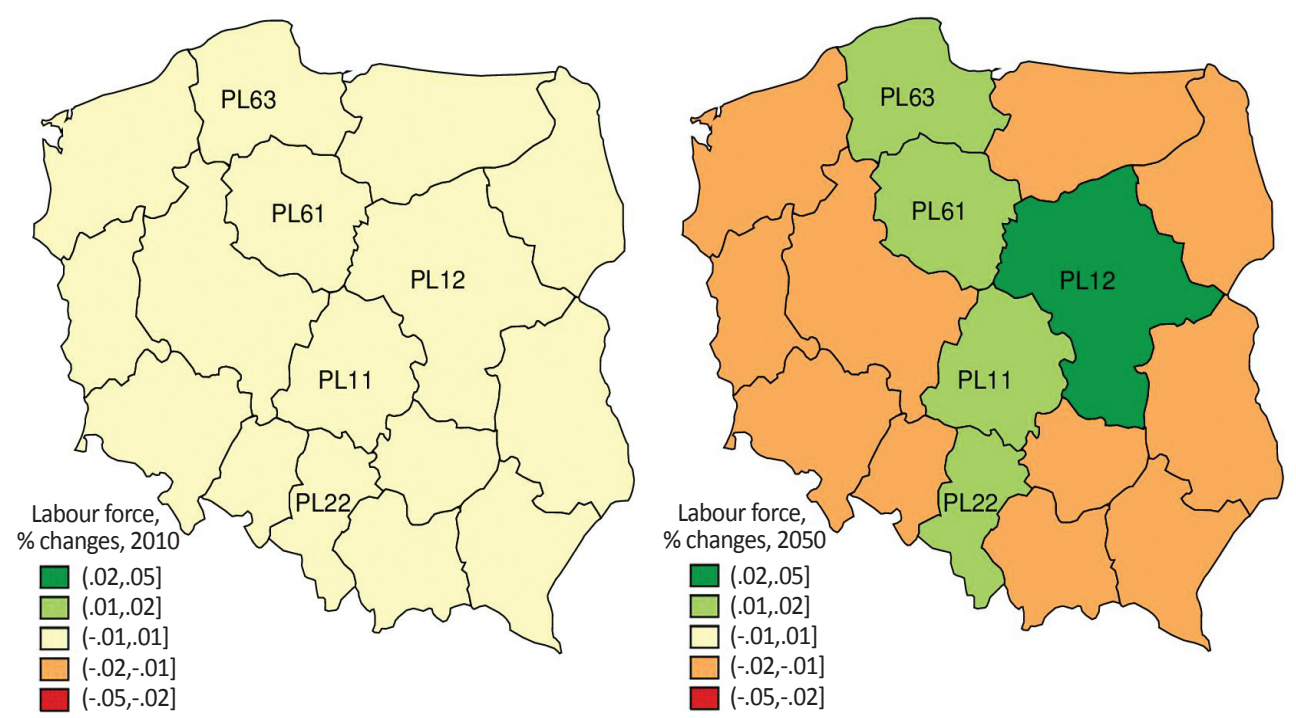

Figure 10 shows short-run (2010) and long-run (2050) impacts of improvement in the regions' accessibility on labour force.

Finally, Figure 10 reports the impact on the size of the regional labour force through inter-regional migration. Our simulations suggest that the five integrating regions with improved market access would attract workers from other regions. In the short-run, the induced relocation of workforce is very low (0.01\%). In the long-run migration slightly increases up to $0.05 \%$. Surprisingly, integration-induced labour migration is very low, but these results are in line with the empirical evidence of low labour migration in the EU (European Commission 2013, Greene and Martins 2013).

\section{Asymmetric Multi-region Integration Scenario}

After sketching the labour market effects of symmetric changes in transportation costs for selected regions, we now turn to simulating the impacts of an asymmetric multi-region integration shock in the whole EU. The symmetric scenario's considered the case where transport costs were lowered in an artificial way with the goal to explore the behaviour of the model. First, we considered a single Belgian region undergoing a decrease of $10 \%$ with respect to all other regions. We then considered the case where a 
group of Polish regions experience a decrease in transport costs between them but not the rest of the world. Now, we consider a scenario which is more relevant for policy, rather than for model evaluation, where transport costs are lowered due to policy, and different regions and the trade links between them are affected in very different ways throughout the EU. This simulation exercise is based on real Trans-European Transport Network (TEN-T) investments. Our approach consists of two steps: (i) simulating the impact of transport infrastructure investments on regions' accessibility; and (ii) simulating the impact of transportation cost reduction on regional income, migration, etc. Improvements in the transport network are measured by kilometres of new infrastructure, number of additional lanes, maximum speed, etc. In the second step, the changes in the accessibility of regions are simulated in an economic model, where the units of measurement are relative prices, wages, employment, migration, etc.

We simulate the impact of the TEN-T investments on regions' accessibility by employing the TRANS-TOOLS (TOOLS for TRansport Forecasting ANd Scenario testing) model of the European Commission. ${ }^{8}$ The TEN-T scenario includes all approved TEN-T priority axes and projects until 2020. The output of the TRANS-TOOLS model are two generalised transportation cost matrices, one for the base year and the other for the TEN-T scenario that have three dimensions such as origin region, $o$, destination region, $d$, and sector, $i$. The simulation results from the TRANS-TOOLS model suggest that completing the TEN-T networks will significantly reduce transportation costs between regions. According to the TRANS-TOOLS model's simulations, through a $14 \%$ reduction in road congestion and improved rail performance, up to $11.2 \%$ time and $3.9 \%$ cost savings will be achieved upon completing the 30 priority axes/projects, which form the 'backbone' of the TEN-T. In addition, the TRANS-TOOLS simulation results suggest that freight transport in the EU will increase by more than two thirds by 2020, and double in the new member states.

Simulations are performed using the TRANS-TOOLS version 2 model.

\footnotetext{
${ }^{8}$ TRANS-TOOLS (TOOLS for TRansport Forecasting ANd Scenario testing) is a European transport network model that has been developed in collaborative projects funded by the European Commission DG JRC and DG TREN. See http://energy.jrc.ec.europa.eu/ transtools for a formal description of the TRANS-TOOLS model.
} 


\section{Figure 11. Asymmetric Multi-Region Integration Scenario}

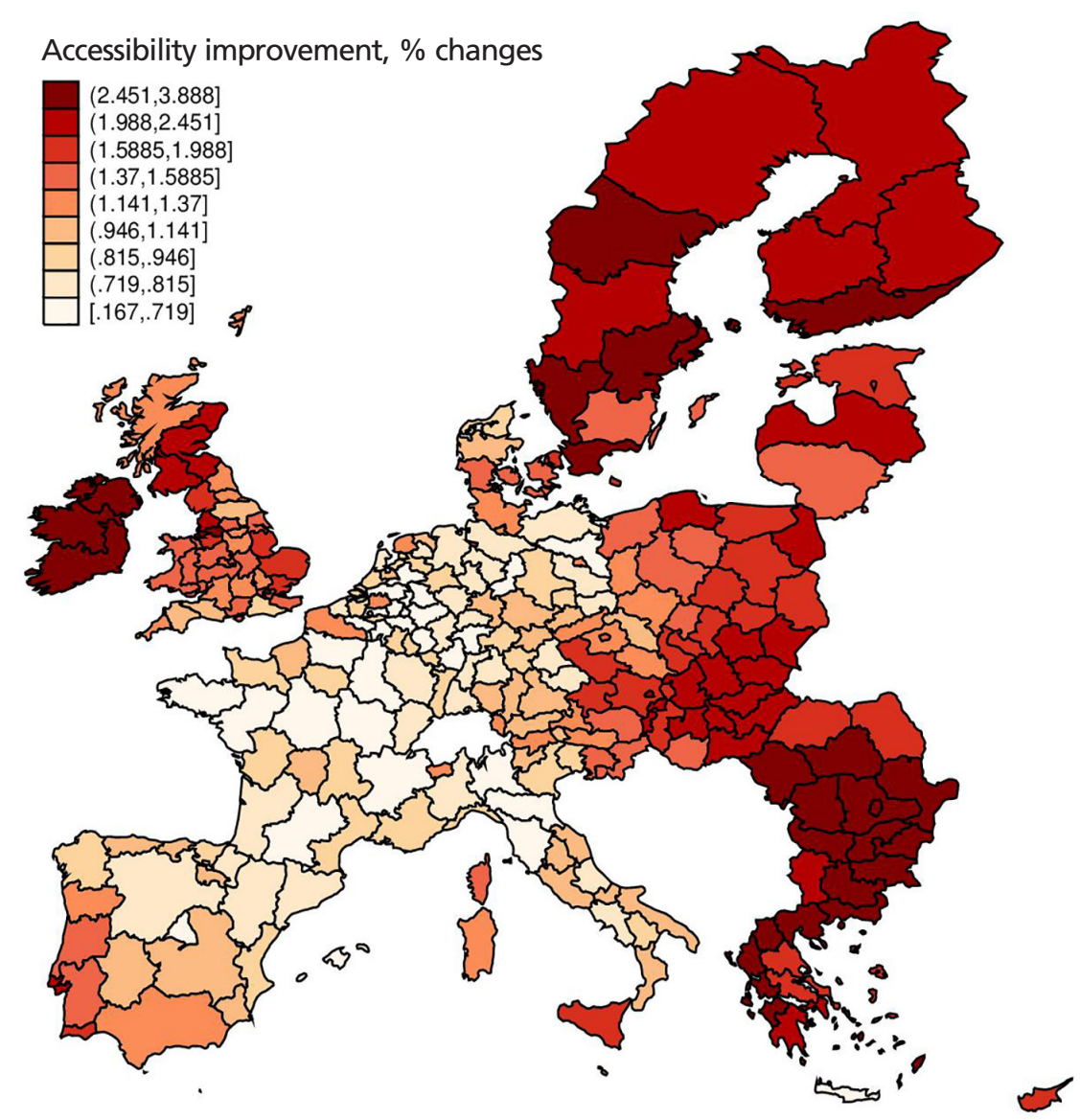

Figure 11 shows improvements in regions' accessibility due to TEN-T investments, changes in percent from the baseline.

In order to illustrate the asymmetric multi-region integration scenario, we have calculated an accessibility indicator for each region, which measures the weighted average transportation costs from region, $o$, to all potential destination regions, $d$. Generalised transportation costs are weighted by the bilateral trade flows between the respective regions. Figure 11 maps these changes in regions' accessibility due to the TEN-T investment for all NUTS2 regions in the EU.

According to Figure 11, the accessibility of the EU peripheral regions would improve relative to the core regions as a result of the TEN-T investments. In terms of accessibility, the largest beneficiaries are the new EU member states, Scandinavian countries, Greece, and Ireland. Also southern Italy, Portugal, southern Spain, Denmark, 
and the UK would benefit substantially from the TEN-T investments. In contrast, accessibility would increase less in the centrally located regions of Luxembourg, Belgium, Netherlands, France, and Germany.

In the second step, we employ the RHOMOLO model to simulate the impact of an asymmetric multi-region integration on regional labour markets. The results of the asymmetric multi-region integration shock on regional labour markets in the EU are reported in Figures 12 15, which show the long-run (2050) impacts on real wages, unemployment, expected income, and labour force, respectively.

\section{Figure 12. Impact on Real Wages of an Asymmetric Multi-Region Integration Shock}

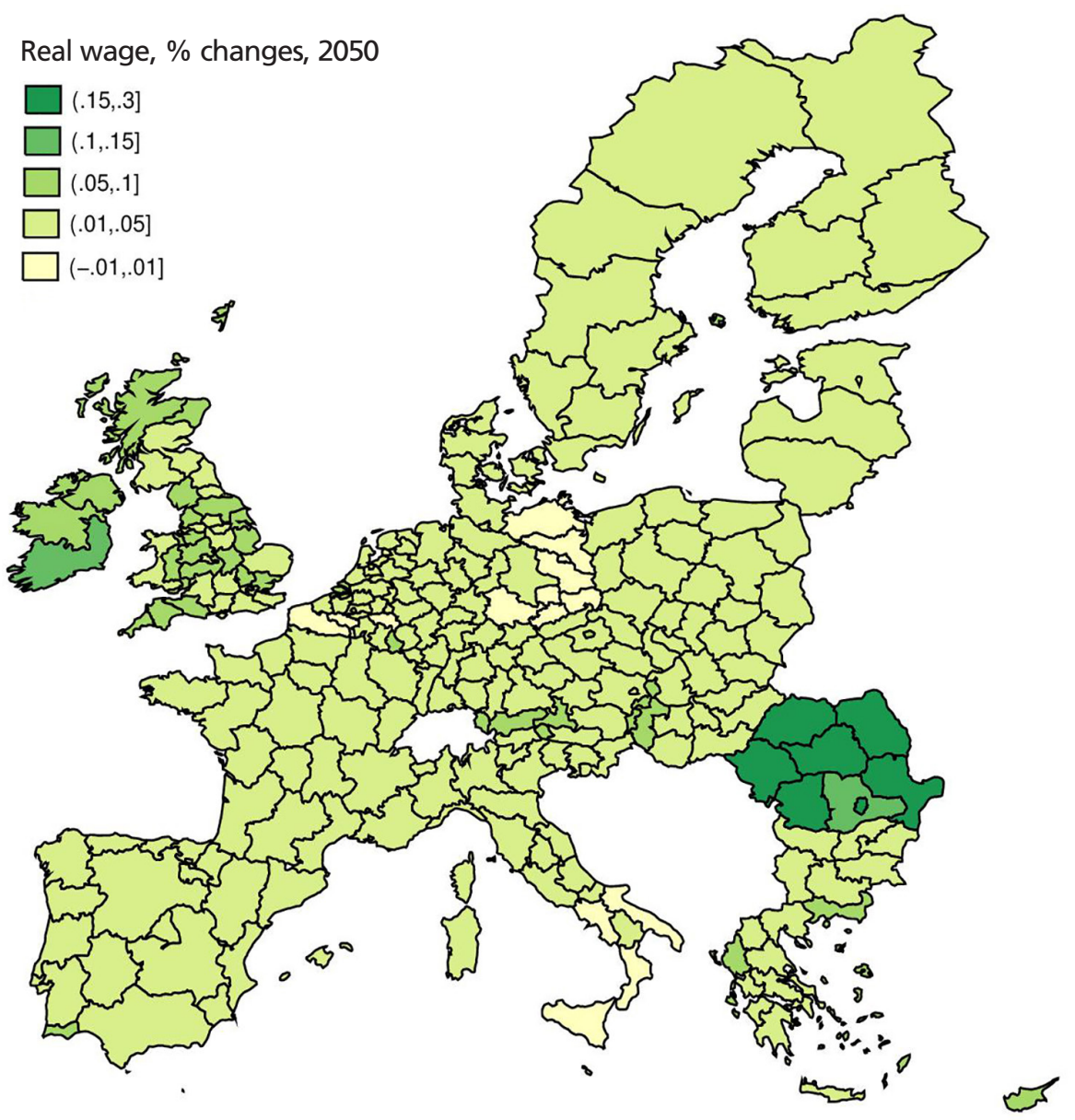

Figure 12 shows long-run (2050) impacts of improvement in regions' accessibility on real wages. 
According to Figure 12, the TEN-T investments would increase real wages in all EU regions in the long-run. The impact on real wages would be the highest in the Romanian regions, up to $0.3 \%$ compared to the baseline.

\section{Figure 13. Impact on Unemployment} of an Asymmetric Multi-Region Integration Shock

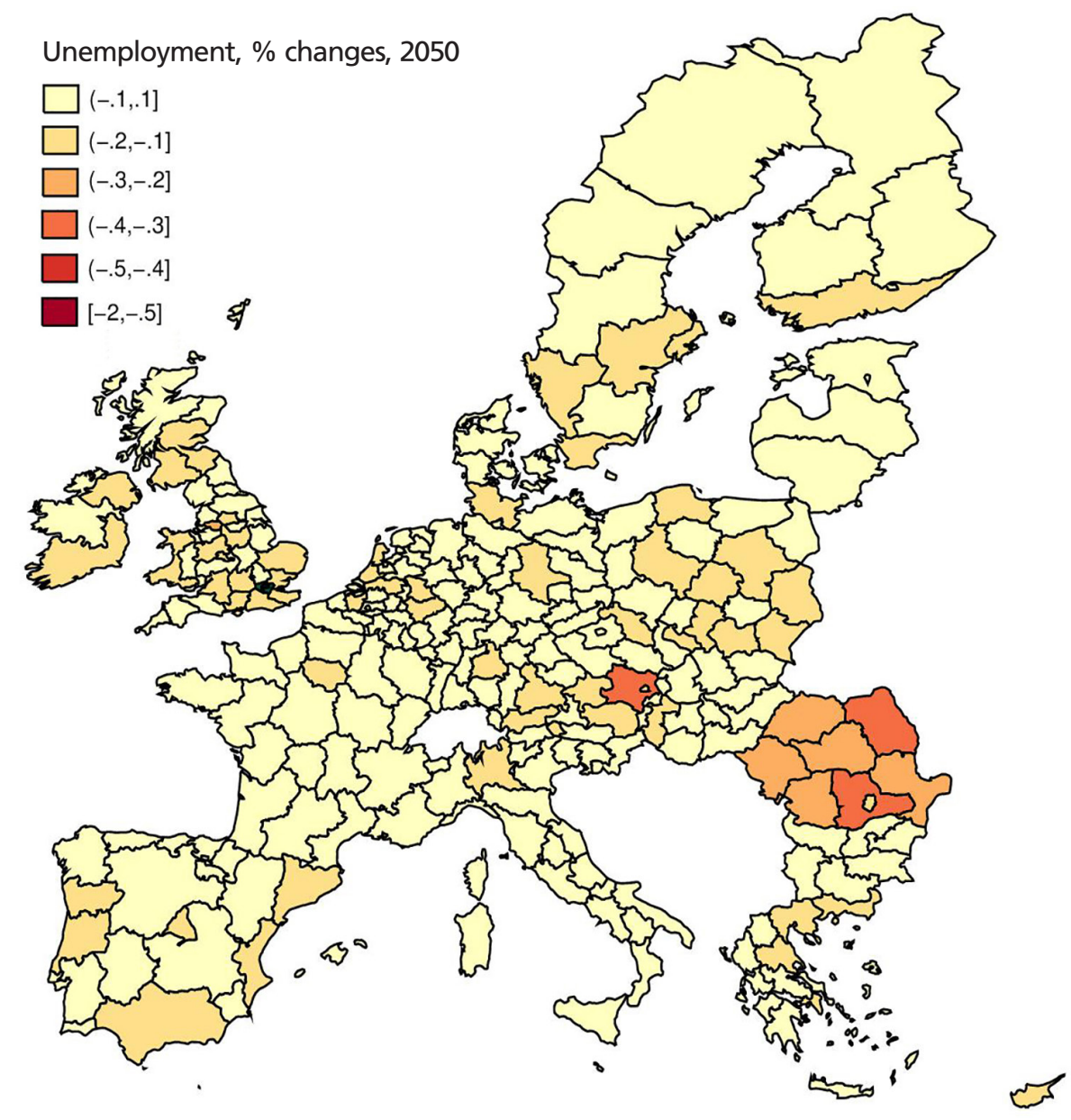

Figure 13 shows long-run (2050) impacts of improvement in regions' accessibility on unemployment.

Figure 13 suggests that the TEN-T investments would reduce unemployment in almost all EU regions in the long-run. Again, the Romanian regions would also gain the most in terms of employment creation, up to $0.5 \%$ compared to the baseline. These results can be best understood, when comparing them to the simulated scenario (Figure 
11), according to which the Romanian regions would benefit extensively from the TEN-T investments. Improving regions' accessibility by around 3\% would increase real wages by around $0.3 \%$ and reduce unemployment by around $0.3 \%$, suggesting a multiplier effect of market access on real wages and unemployment of around 0.1 .

\section{Figure 14: Impact on Expected Income} of an Asymmetric Multi-Region Integration Shock

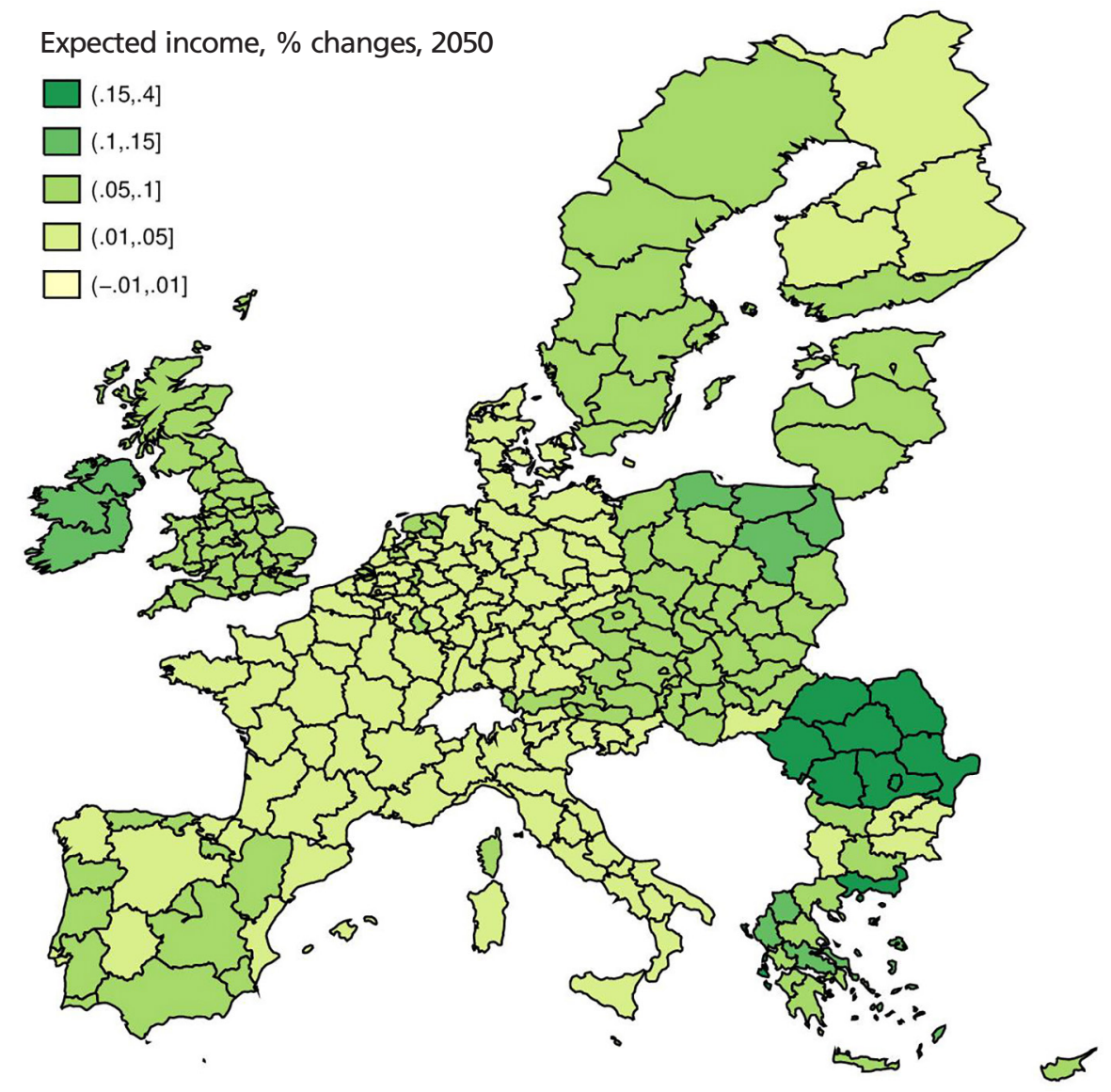

Figure 14 shows long-run (2050) impacts of improvement in regions' accessibility on expected income.

The results from Figures 12 and 13 are confirmed by the simulated impact on the expected income as shown in Figure 14. Due to improved market access, expected income would grow the fastest in the Romanian regions, north-east Poland, and Ireland. In the long-run, the TEN-T investments would also increase income in all other EU 
Modelling Migration and Regional Labour Markets: an Application of the New Economic Geography Model RHOMOLO

regions. As above, the multiplier effect of the regions' improved accessibility on expected income is around 0.1 .

\section{Figure 15. Impact on Labour Force}

\section{of an Asymmetric Multi-Region Integration Shock}

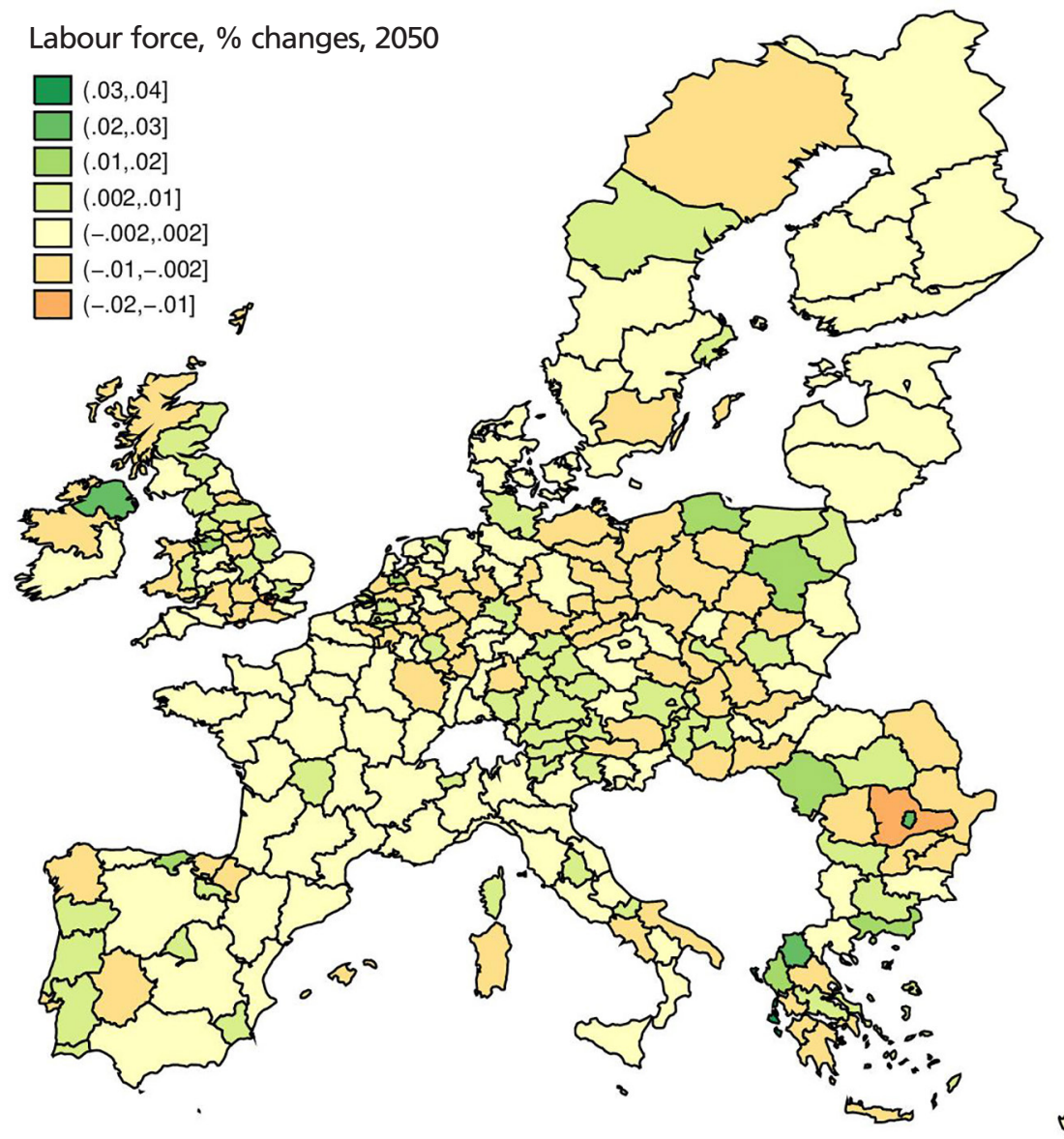

Figure 15 shows long-run (2050) impacts of improvement in regions' accessibility on labour force.

In almost every EU member state there are some regions, which would lose workforce, and some other regions, which would gain workforce. In most cases, however the capital city regions would gain workforce. These results confirm the importance of national borders, and the observed low international labour mobility within the EU. The large differences in the TEN-T investment between countries do not translate into significant international migration flows, and the regional changes 
in the size of the labour force rather reflect within-country migration in response to relative changes in regions within countries. These results confirm that there are important differences in the response to macroeconomic shocks between the regional and national labour markets. Our results also suggest that labour migration, as a channel of labour market adjustment to macro-economic shocks, is less important than wages and unemployment. The multiplier effect of a region's improved accessibility on the net labour migration is around 0.01 compared to 0.1 for wages and unemployment. These results are in line with the empirical evidence for the EU (European Commission 2013).

Similar to the results reported in Sections B and C, the dynamics of the short-run and medium-run results (not reported) suggest that the relationship between market access, wage rate, labour demand, and supply is complex. This complexity is due to the underlying assumptions of the theoretical framework and some intuition on the possible causes was provided in subsections B and C, that is, changes in regions' accessibility increase market access, resulting in more output per firm, higher demand for labour, and hence higher wages. Higher wages, in turn, would attract workers from other regions. On the other hand, a decrease in inter-regional transportation costs increases competition, and reduces firm profits and wages. Lower wages may induce workers to leave the integrating regions. Given the region's characteristics, the total effect is complex in the level of economic integration and spatial location. ${ }^{10}$ Our results clearly show the benefit of analysing such non-linear relationships between market access, wage rate, labour demand and supply, as well as spatial inter-dependencies in a dynamic spatial general equilibrium framework, where endogenous variables are solved inter-temporally.

\section{Conclusions}

The present paper describes the newly developed dynamic spatial general equilibrium model RHOMOLO where the labour market equilibrium is determined by firms' labour demand, a wage-curve determining unemployment, and inter-regional labour migration. The RHOMOLO model is parameterised after estimating the key

\footnotetext{
${ }^{11}$ Note that, according to the underlying conceptual framework, gross labour migration may be larger (and empirically is larger) than net labour migration.

${ }^{12}$ See Kancs (2013) for a detailed description of agglomeration and dispersion forces and mechanisms in RHOMOLO.
} 
structural parameters such as elasticities of inter-regional labour migration.

With the proposed dynamic spatial general equilibrium approach to regionally integrated labour markets, we carried out simulations on the effects of transportation costs in three different regional integration scenarios on regional labour markets. In the first scenario, transportation costs to and from a single region are reduced proportionally by 10 percent. This scenario allows us to trace the dynamics of an isolated shock through the regional labour markets over time. In the second scenario, transportation costs are reduced symmetrically between selected regions. The impacts in this scenario are more complex. In the third scenario, transportation costs between all EU regions are reduced asymmetrically and simultaneously. This scenario is associated with the approved Trans-European Transport Network (TEN-T) priority projects until 2020.

Our results confirm that wages and unemployment are the most important channels of adjustment to macro-economic shocks in the EU. Improving accessibility by around $3 \%$ would increase real wages by around $0.3 \%$ and reduce unemployment by around $0.3 \%$, suggesting a multiplier effect of market access on real wages and unemployment of around 0.1 . In contrast, labour migration, and especially international migration, plays only a secondary role in regional labour market adjustments in the EU. The multiplier effect of the improved accessibility on net labour migration is around 0.01 compared to 0.1 for wage and unemployment. These results are new and have not been reported in the literature before.

Acknowledgements: The authors acknowledge helpful comments and valuable contributions from Stefan Boeters, Steven Brakman, Johannes Broecker, Olga Diukanova, Leen Hordijk, Artem Korzhenevych, Hans Lofgren, Philippe Monfort, Mark Thissen, Charles van Marrewijk, Renger Herman van Nieuwkoop, two anonymous referees of the Journal, participants of the European Regional Science Association, as well as participants of seminars and workshops at the European Commission. The authors are solely responsible for the content of the paper. The views expressed are purely those of the authors and may not in any circumstances be regarded as stating an official position of the European Commission.

Received 22 April 2013, Revised 04 September 2013, Accepted 14 November 2013 


\section{References}

Agenor, P.-R. (1996), “The labor market and economic adjustment”, IMF Staff Papers, 43 (2): 261-335.

Bentivogli, C. and Pagano, P. (2003), "Regional disparities and labour mobility: The Euro-11 versus the USA", Labour, 13 (3): 737-760.

Berry, S. (1994), "Estimating discrete-choice models of product differentiation", The RAND Journal of Economics, 25 (2): 242-262.

Blanchard, O. J. and Katz, L. F. (1992), "Regional evolutions", Brookings Papers on Economic Activity, 23 (1): 1-76.

Blanchflower, D. and Oswald, A. (1995), "The wage curve", MIT press.

Boeters, S. and Savard, L. (2012), “The Labour Market in Computable General Equilibrium Models", in Handbook of Computable General Equilibrium Modeling, Peter B. Dixon and Dale Jorgenson (Editors), 1645-1711.

Brandsma, A., Kancs, D., Monfort, P. and Rillaers, A. (2013), "RHOMOLO: A Dynamic Spatial General Equilibrium Model for Assessing the Impact of Cohesion Policy”, JRC-IPTS Working Paper Series JRC81133, European Commission, DG Joint Research Centre.

Decressin, J. and Fatás, A. (1995), "Regional labor market dynamics in Europe", European Economic Review, 39 (9): 1627-1655.

Di Comite, F. and Kancs, D. (2013), "Modelling of Agglomeration and Dispersion in RHOMOLO”, JRC-IPTS Working Paper Series JRC81349, European Commission, DG Joint Research Centre.

Elhorst, J. P. (2003), “The mystery of regional unemployment differentials: Theoretical and empirical explanations", Journal of Economic Surveys, 17 (5): 709-748.

European Commission (2013), "Labour Market Developments in Europe 2013", European Economy 2013/05, DG for Economic and Financial Affairs.

Greene, W. H. and Martins, A. P. (2013), "Striking features of the labor market: Theory", Journal of Economics and Econometrics, 56 (2): 1-24.

Grogger, J. and Hanson, G. (2011), "Income maximization and the selection and sorting 
of international migrants", Journal of Development Economics, 95 (1): 42-57.

Kancs, D. (2011), "Labour migration in the enlarged EU: A new economic geography approach", Journal of Economic Policy Reform, 14 (2): 171-188.

Krugman, P. (1991), "Increasing returns and economic geography”, Journal of Political Economy, 99 (3): 483-499.

McFadden, D. (1973), “Conditional logit analysis of qualitative choice behavior", In P. Zarembka (ed.), Frontiers in Econometrics, New York: Academic Press.

Obstfeld, M. and Peri, G. (2000), "Regional non adjustment and fiscal policy: lessons for EMU", Intranational Macroeconomics.

Persyn, D.,Kancs, D. and Torfs, W. (2014), "Regional labour market dynamics in the EU: Modelling participation, employment and migration decisions in the regional CGE model Rhomolo", JRC-IPTS Working Paper Series JRC89537, European Commission, DG Joint Research Centre.

— and Torfs, W. (2012), "A gravity equation for commuting", VIVES Discussion Paper Series 33, Faculty of Economics and Business, University of Leuven.

Pissarides, C. A. and Wadsworth, J. (1989), "Unemployment and the inter-regional mobility of labour", Economic Journal, 99 (397): 739-55.

Potters, L., Conte, A., Kancs, d., and Thissen, M.(2013), "Data needs for regional modelling”, IPTS Working Paper Series JRC80845, European Commission, DG Joint Research Centre.

Puga, D. (2002), "European regional policies in light of recent location theories", Journal of Economic Geography, 2 (4): 373-406.

Sanz-de Galdeano, A. and Turunen, J. (2006), "The Euro Area Wage Curve”, Economics Letters, 92 (1): 93-98.

Schmidheiny, K. and Brülhart, M. (2011), "On the equivalence of location choice models: Conditional logit, nested logit and poisson", Journal of Urban Economics, 69 (2): 214-222.

Sorensen, T., Fishback, P., Allen, S. and Kantor, S. (2007), "Migration Creation, Diversion, and Retention: New Deal Grants and Migration 1935-1940”, NBER working paper series, National Bureau of Economic Research. 